\title{
O MODELO COGNITIVO DE BECK COMO FERRAMENTA DE IDENTIFICAÇÃO DE CRENÇAS RELACIONADAS À INIBIÇÃO CRIATIVA EM MÚSICA
}

\author{
Beck's cognitive model as a tool for \\ identifying beliefs related to creative \\ inhibition in music
}

\author{
El modelo cognitivo de Beck como \\ herramienta para identificar creencias \\ relacionadas con la inhibición creativa en la \\ música
}

\author{
LUCIANO DA COSTA NAZARIO \\ Universidade Federal do Rio Grande \\ lucomposer@yahoo.com.br
}

EDUARDO TEIXEIRA MARTINS Universidade Federal do Rio Grande eduardomartins1998@outlook.com

\author{
ALEX SANDRO RODRIGUES MARTINS \\ Universidade Federal do Rio Grande \\ alexsmartins182@gmail.com
}

\begin{abstract}
Resumo: Neste artigo apresentamos o modelo cognitivo de Beck como uma ferramenta que poderá auxiliar o educador a identificar crenças consideradas inibidoras à ação criativa em música. Através da realização de uma pesquisa baseada na prática (practice-based research), coletou-se os depoimentos de um dos participantes voluntários com vistas a exemplificar os procedimentos adotados por essa abordagem no contexto da prática musical. Como resultado, o modelo se mostrou eficaz, uma vez que permitiu o rastreamento de pensamentos automáticos, crenças centrais e subjacentes consideradas disfuncionais à ação criativa, sendo estas associadas a princípios axiológicos capazes de inibir a livre manifestação musical.
\end{abstract}

Palavras-chave: Modelo cognitivo. Criatividade musical. Crenças centrais.

\begin{abstract}
In this article, we present the Beck's cognitive model as a tool to help the educator to identify beliefs considered inhibitive to creative action in music. By conducting a practice-based research, we collected the testimonies of one of the volunteer participants to exemplify the procedures adopted by this approach in the context of musical practice. As a result, the model proved to be effective, since it allowed the tracking of automatic thoughts, central and underlying beliefs considered to be dysfunctional to creative action and which are associated with axiological principles capable of inhibiting free musical expression.
\end{abstract}

Keywords: Cognitive model. Musical creativity. Central beliefs.

Resumen: En este artículo presentamos el modelo cognitivo de Beck como una herramienta que puede ayudar al educador a identificar creencias que inhiben la acción creativa en la música. Mediante la realización de una investigación basada en la práctica (practice-based research), se recogieron las declaraciones de uno de los participantes voluntarios para ejemplificar los procedimientos adoptados por este enfoque en el contexto de la práctica musical. Como resultado, el modelo demostró ser efectivo ya que permitió el seguimiento de pensamientos automáticos, creencias básicas y subyacentes consideradas disfuncionales para la acción creativa, y estos se asociaron con principios axiológicos capaces de inhibir la libre manifestación musical.

Palabras clave: Modelo cognitivo. Creatividad musical. Creencias centrales. 


\section{INTRODUÇÃO}

Desde meados do século XX, a literatura científica sobre o estudo da criatividade tem evidenciado numerosos fatores capazes de inibir o potencial criativo dos indivíduos. Diferentes abordagens teóricas ${ }^{1}$ têm apontado para agentes intrapsíquicos e externos que podem impactar negativamente tanto o comportamento criativo dos indivíduos quanto a maneira como estes constroem seus autoconceitos. Fatores, tais como: (a) a não promoção de condições favoráveis à saúde mental (e.g. Maslow, 1968; Rogers, 1969), (b) a inibição do gesto espontâneo (e.g. Winnicott, 1990), (c) as barreiras cognitivas, motivacionais e ambientais (e.g. Amabile et al., 1986; Sternberg, 2006), (d) as esferas sociais e politicas desfavoráveis à manifestação criativa (e.g. Csikszentmihalyi, 1996; Simonton, 2000) são alguns dos agentes que podem contribuir ao bloqueio criativo.

$\mathrm{Na}$ área da Música, pesquisas têm denunciado procedimentos que inibem a criatividade no contexto educacional, apresentando a existência de modelos pedagógicos capazes de impossibilitar o desenvolvimento criativo dos estudantes nos mais diversos contextos escolares. Abordagens comuns no ensino de música de concerto realizado em conservatórios e universidades, por exemplo, tendem a: (a) destacar os cânones que enfatizam os grandes gênios da música clássica, privilegiando a composição como um ato criativo individual pertencente a membros de uma seleta elite, os quais detêm os conhecimentos necessários para se expressarem criativamente $^{2}$; e (b) focar-se exclusivamente na expertise técnica e aprendizagem teórica, pouco considerando uma educação musical mais humanista, sensibilizadora e atenta à subjetividade criativa do educando (e.g., para estudos internacionais, cf., Allsup; Benedict, 2008, p. 170; Burnard 2012a, p. 1; para estudos realizados no Brasil, cf., Glaser, 2005, p. 46-60; Glaser, 2007, p. 3-4; Albino, 2009, p. 25-26).

Hill, em sua pesquisa realizada na academia Sibelius (Universidade de Helsinki, Finlândia), relata a insatisfação de pedagogos de música folclórica em relação à arte musical ocidental, ao proporcionar virtualmente nenhuma oportunidade de improvisação e limitar a composição a uma seleta elite talentosa ${ }^{3}$ (Hill, 2009, p. 90). Em sua pesquisa intercultural realizada em Los Angeles (USA), Helsinki (Finlândia) e Cape Town (África do Sul), Hill observou sistemas de crenças inibidoras da criatividade musical

\footnotetext{
${ }^{1}$ Teoria psicanalítica, psicologia humanista, modelo componencial, teoria do investimento em criatividade, perspectiva de sistemas e historiométrica, dentre outras.

2 Pamela Burnard observa que a criatividade, nesses contextos, é entendida como uma prática incorporada no indivíduo (criatividade individual) e está profundamente ligada ao individualismo heroico dos grandes compositores e gênios (Burnard, 2012a, 2012b).

${ }^{3}$ A autora observa que suas percepções, apesar de parciais, são fundamentadas em pesquisas realizadas por Campbell (1991), Sancho-Velázquez (2001) e Moore (1992) quanto ao declínio da improvisação na arte musical ocidental; Kingsbury (1988), com relação à construção social do "talento"; e Cook (2006) em relação à crença romântica de que compositores deveriam ser gênios divinamente inspirados (Hill, 2009, p. 111).
} 
compartilhadas por diferentes comunidades de músicos (músicos de jazz, música de concerto e música folclórica). A partir dos depoimentos de seus respondentes, a autora identificou crenças associadas à conformidade com normas sociais, à autoimagem negativa, ao feedback destrutivo sofrido por professores e pares, à impossibilidade de tomar decisões, ao perfeccionismo, dentre outros agentes inibidores (Hill, 2018).

Da mesma forma, estudos em psicologia social têm demonstrado a influência social nas atitudes individuais, crenças, pensamentos e sentimentos (e.g., Festinger, 1954; Asch, 1955). Conforme observou Alencar e Fleith, a literatura científica ${ }^{4}$ tem sinalizado que muitas pessoas não têm consciência do quanto seus comportamentos são influenciados por fatores externos capazes de bloquear o desenvolvimento e a expressão criativa, tampouco dos recursos que elas poderiam utilizar para não se deixar abater por tais fatores (Alencar; Fleith, 2003, p. 102). Por esses motivos, identificar que crenças o sujeito possui sobre si mesmo, sobre os outros e sobre o mundo é o primeiro passo para a mudança comportamental. Em uma perspectiva construtivista, compreender quais crenças e paradigmas internalizados os estudantes trazem consigo é fundamental para uma correta análise e elaboração de quaisquer planos pedagógicos que visem ao aprimoramento criativo. O desenvolver criativo (prefixo des - oposição mais a palavra envolver) implica "tirar o que envolve ou cobre" (Houaiss, 2009) a livre manifestação criativa. Entendemos, portanto, que o desenvolvimento criativo em música não está apenas na relação ser humano versus material sonoro (técnicas, conhecimentos etc.), mas na própria correspondência entre ser humano versus ser humano, na relação consigo mesmo, com os outros e com a realidade ao seu redor. A identificação de crenças inibidoras permitirá, assim, abrir caminhos para o pleno desenvolvimento criativo.

Sendo assim, a proposta deste artigo é apresentar o modelo cognitivo alvitrado por Aaron T. Beck como uma ferramenta que poderá facilitar ao educador musical identificar e relacionar pensamentos, sentimentos e crenças individuais e coletivas em sala de aula. O modelo cognitivo é fundamentalmente utilizado em terapia cognitiva, porém entendemos ser possivel e relevante sua aplicabilidade em música, principalmente no que tange ao reconhecimento de crenças disfuncionais associadas à inibição criativa. Esse estudo, em específico, foi realizado pelo coordenador (da área da Música) e dois colaboradores (da área de Psicologia) do grupo de estudos sobre criatividade em música da Universidade Federal do Rio Grande, o qual é constituído por uma equipe multidisciplinar composta por estudantes e profissionais da área de Música, Psicologia, Antropologia, Pedagogia, Artes Visuais e Letras.

\footnotetext{
${ }^{4}$ As autoras se fundamentam em pesquisas realizadas por Adams (1986), Alencar (1997), Morejón (1996, 2001), VanDemark (1991), Von Oech (1990), dentre outros (Alencar; Fleith, 2003, p. 102).
} 
Os depoimentos apresentados neste artigo foram retirados de relatos pessoais de um dos músicos voluntários que participaram desse estudo, o qual, assim como os demais, teve pleno conhecimento da natureza das atividades de pesquisa e assinou o Termo de Consentimento Livre e Esclarecido (TCLE), dando as devidas permissões para contribuir com essa investigação. A interpretação da fala do respondente teve como base os fundamentos teóricos do modelo cognitivo, focando na análise dos problemas presentes e nas experiências psicológicas conscientes. Os fundamentos do modelo são apresentados a seguir.

\section{O Modelo Cognitivo DE BeCK}

A teoria cognitiva considera a cognição ${ }^{5}$ a chave para os transtornos psicológicos (Beck; Alford, 2000, p. 23). Desenvolvida por Aaron T. Beck na Universidade da Pensilvânia no início da década de 60 do século XX, o modelo cognitivo pauta-se na hipótese de que as emoções e os comportamentos de uma pessoa são influenciados pelas percepções que ela possui dos eventos (Beck, 2014, p. 55).

O modelo cognitivo tem suas bases no estoicismo e em filosofias orientais budistas e taoístas. O filósofo estoico Epictetus dizia que os homens não são perturbados pelas coisas, mas pela visão a respeito das coisas (Bonforte, 1955, p. 92). Uma mesma situação produz, portanto, reações distintas em diferentes pessoas, e uma mesma pessoa pode ter reações distintas a uma mesma situação (Pereira; Rangé, 2011, p. 21). Partindo deste pressuposto, a interpretação que cada indivíduo realiza das situações de sua vida possui maior relevância na forma como ele se sente do que os acontecimentos em si. Segundo Beck (1976), para melhor entender as reações emocionais a um acontecimento, é preciso distinguir o significado público de uma ocorrência (a definição formal e objetiva de um evento) de seu significado pessoal (a interpretação do individuo) (Beck, 1976, p. 39). Ao reprovar em determinada prova, por exemplo (a qual possui o significado público de testar conhecimentos), algumas pessoas podem se motivar em tentar realizá-la novamente, enquanto outras podem se frustrar e se julgar incapazes de obter aprovação futura. O mesmo acontecimento é passivel de inúmeros significados pessoais, os quais influenciam diretamente a forma como cada indivíduo reage.

Para Beck, tais significados ${ }^{6}$ são estabelecidos e selecionados a partir de esquemas prévios que os sujeitos possuem sobre si mesmos, sendo a natureza do conteúdo do esquema influenciado por eventos ambientais (Beck; Haigh, 2014, p. 5). No campo da psicologia cognitiva, o termo esquema é usado para nomear um padrão imposto à realidade ou à

\footnotetext{
${ }^{5}$ Cognição é entendida pelos autores como o processo que envolve deduções sobre nossas experiências e sobre a ocorrência e controle de eventos futuros (Beck; Alford, 2000, p. 23).

${ }^{6}$ Beck e Alford se referem ao termo significado como à interpretação da pessoa sobre um determinado contexto e da relação daquele contexto com o self (Beck; Alford, 2000, p. 24).
} 
experiência para ajudar as pessoas a explicá-la, ou seja, serve para mediar a percepção e para guiar as respostas. É, portanto, uma estrutura cognitiva que molda as imagens, interpretações e percepções do indivíduo (Beck, 1976, p. 226).

Seguindo a mesma premissa, Young entende que um esquema pode ser adaptativo e auxiliar positivamente o sujeito durante as situações da sua vida ou pode ser desadaptativo, bloqueando totalmente ou parcialmente ações e comportamentos funcionais. Segundo Young, os esquemas podem ser rígidos ou flexíveis e podem se formar a qualquer momento da nossa vida, possuindo niveis de gravidade e penetração diferentes (Young et al., 2008, p. 22-23) ${ }^{7}$.

O conteúdo específico dos esquemas são as crenças centrais (ou nucleares), que podem estar associadas ao self, aos outros e ao mundo (Beck, 2014, p. 250). Uma vez que o pensamento frequentemente se associa a um esquema, há a possibilidade de ocorrer determinadas construções cognitivas com falhas específicas (distorções cognitivas), incluindo erros no conteúdo cognitivo (significado), no processamento cognitivo (elaboração de significado), ou ambos (Beck; Alford, 2000, p. 25). Um esquema de desamparo ${ }^{8}$ poderia englobar, por exemplo, crenças centrais disfuncionais como as apresentadas no Quadro 1 a seguir:

\begin{tabular}{c|c|c}
\hline \multicolumn{3}{c}{ Esquema (desamparo) } \\
\hline $\begin{array}{c}\text { Crença central 1 } \\
\text { (sobre si mesmo) }\end{array}$ & $\begin{array}{c}\text { Crença central 2 } \\
\text { (sobre os outros) }\end{array}$ & $\begin{array}{c}\text { Crença central 3 } \\
\text { (sobre o mundo) }\end{array}$ \\
\hline Sou incapaz & $\begin{array}{c}\text { Os outros são melhores } \\
\text { do que eu }\end{array}$ & $\begin{array}{c}\text { O mundo demanda altos } \\
\text { padrões de desempenho }\end{array}$ \\
\hline
\end{tabular}

Quadro 1: Exemplo de crenças centrais disfuncionais associadas ao esquema de desamparo.

As crenças centrais são compreensões duradouras, tidas como verdades, enraizadas, inquestionáveis e capazes de influenciar a percepção pessoal. Ao se deparar com algum evento que ative esta crença, o indivíduo começa a avaliar as situações a partir das lentes desta crença. Quando ocorre algo que se opõe às verdades estabelecidas por ela, o sujeito tende a desconsiderar este acontecimento ou a deformá-lo, reafirmando as ideias trazidas pela crença central (Beck, 2014, p. 57). A Figura 1 apresenta uma representação do modelo cognitivo de Beck, o qual evidencia o processo de retroalimentação de uma crença central:

\footnotetext{
${ }^{7}$ Embora a Terapia dos Esquemas proposta por Young possua uma diferente abordagem e ênfase, do ponto de vista conceitual, apresenta muitos pontos em comum com a terapia cognitivo-comportamental (Young et al., 2008, p. 58).

${ }^{8}$ As crenças centrais geralmente associadas ao desamparo são: "sou incompetente", "sou ineficiente", "não consigo fazer nada direito", "sou um perdedor" etc. (Beck, 2014, p. 254).
} 


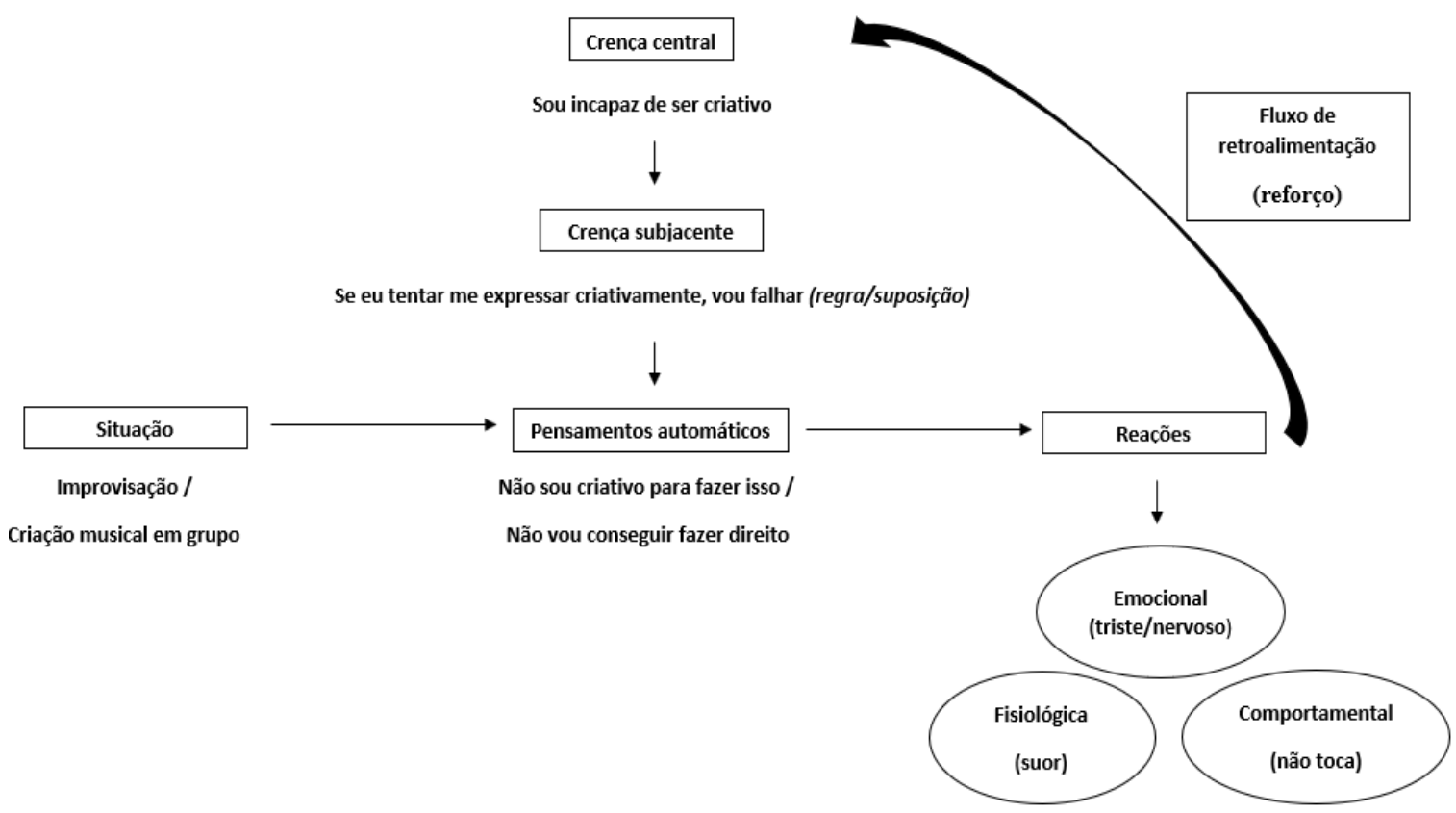

Figura 1: Modelo cognitivo de Beck adaptado de Caminha e Vasconcelos (2007). Fonte: Caminha et al., 2003 apud Caminha; Vasconcelos, 2007, p. 26.

Conforme a Figura 1, a crença central (situada na parte superior do modelo) é a base que dá origem às crenças subjacentes (ou intermediárias), as quais postulam atitudes, regras e pressupostos que influenciam a forma como os sujeitos se comportam. As crenças subjacentes oferecem material para os pensamentos automáticos, os quais são o start do esquema mental do indivíduo e ocorrem diante de uma situação que provoque um estímulo interno ou externo (Caminha; Vasconcellos, 2003, p. 27). Os pensamentos automáticos surgem de forma espontânea, são fugazes e trazem alguma forma de avaliação ou interpretação do acontecimento, desencadeando respostas emocionais, comportamentais e/ou fisiológicas (Beck, 2014, p. 55). Embora diversos pensamentos automáticos possuam conteúdos benéficos para os sujeitos, muitos destes podem ser caracterizados como disfuncionais, distorcendo a realidade e limitando o indivíduo em suas potencialidades. Não há uma reflexão sobre a validade de seu conteúdo, quase sempre sendo entendido como verdade.

Conforme visto anteriormente, uma miriade de situações pode promover a inibição criativa em música. Fatores psicológicos, socioculturais, educacionais, ambientais e paradigmáticos afetam diretamente a autopercepção dos indivíduos. Na figura acima apresentamos um exemplo hipotético de um esquema de desamparo no qual o indivíduo se percebe como "incapaz de ser criativo" (crença central), tendo como pressuposto a crença subjacente "Se eu tentar me expressar criativamente, vou falhar". A partir dessa construção, o sujeito, ao se deparar com uma oportunidade de se expressar criativamente (criação em grupo, improvisação etc.), tenderá a formular pensamentos automáticos associados a esta crença ("não sou 
criativo para fazer isso", "não vou conseguir fazer direito"), suscitando, muito provavelmente, reações emocionais (tristeza, nervosismo etc.), fisiológicas (suor etc.) e comportamentais (como evitar tocar ou participar de situações similares, por exemplo). Ao falhar, a crença central é reforçada, principalmente se o indivíduo experienciar uma reação negativa do grupo. A partir da identificação de tais crenças, o educador pode dar início ao processo de reconstrução e ressignificação, possibilitando a emergência de comportamentos mais favoráveis ao desenvolvimento criativo do educando.

\section{PROCEDIMENTOS ADOTADOS PARA A COLETA E ANÁLISE DE DADOS}

Os depoimentos apresentados neste artigo foram coletados a partir de uma oficina de música (laboratório de criação musical) realizada na Universidade Federal do Rio Grande no segundo semestre de 2018. A oficina é composta por um trabalho pedagógico (com proposições técnicas e procedimentos para o desenvolvimento criativo) e investigativo (envolvendo coleta de dados a partir da performance e relatos dos participantes), os quais atuam de forma complementar nesse estudo. Trata-se de uma pesquisa baseada na prática (practice-based research), isto é, uma investigação realizada com o objetivo de obter novos conhecimentos a partir da prática e dos resultados dessa prática (Candy, 2006, p. 1). Na pesquisa baseada na prática, os artefatos criativos são a base para a construção do conhecimento, buscando-se responder questões relacionadas ao processo criativo a partir de uma discussão crítica que leva em consideração o significado e o contexto em que os artefatos criativos foram originados (Skains, 2018, p. 86).

Na oficina de música realizada na Universidade Federal do Rio Grande, a investigação teve como foco compreender o processo de desenvolvimento criativo através de atividades experimentais (voltadas à improvisação musical idiomática e não idiomática) e por meio de conversas e troca de experiências. O grupo de participantes investigados era composto majoritariamente por músicos amadores (os quais possuíam outras profissões ou estudavam em outras áreas), um músico profissional (professor de música da rede básica de ensino) e outro em fase de profissionalização (graduando em Música). Os participantes eram adultos e já possuíam, no mínimo, mais de cinco anos de prática musical. Durante os encontros ocorreram diversas conversas e performances musicais, sendo todas as ações registradas em áudio e audiovisual (totalizando 18h28min de gravação), além de questionários preenchidos ao final das atividades. As conversas tinham por objetivo:

a) Proporcionar um ambiente dialógico-reflexivo considerando os estados afetivos, os significados e a maneira como os participantes comunicam suas autoimagens; 
b) Identificar, através dos relatos, determinados princípios axiológicos ${ }^{9}$ capazes de inibir a livre manifestação da criatividade musical dos participantes.

Para facilitar o estabelecimento de um ambiente dialógico-reflexivo item (a) -, foi contemplada uma relação mais humanista, segundo a perspectiva proposta por Rogers (1959), através de uma pedagogia que estimule a aceitação de si mesmo, a autoconfiança e uma maior flexibilidade nas percepções (Rogers, 1959, p. 232). Os encontros se configuraram não apenas como um momento de realização musical, mas como um grupo de conversa onde havia espaço para discussões que abrangiam os mais diversos tópicos.

Cabe salientar que a abordagem humanista foi utilizada exclusivamente para fins pedagógicos, sem competir com o modelo cognitivo, uma vez que ambas as abordagens se diferenciam quanto aos seus procedimentos. Enquanto o modelo cognitivo busca, essencialmente, uma descoberta guiada utilizando-se principalmente de questionamentos socráticos (Santos; Medeiros, 2017, p. 205), o humanismo procura acompanhar o pensamento do participante, não guiá-lo (Rogers; Kinget, 1977 , p. 26). A abordagem humanista foi utilizada, portanto, para estimular a confiança e facilitar o relato dos participantes. Para isso, enfatizou-se as atitudes de (a) congruência, (b) aceitação positiva incondicional e (c) compreensão empática, propostas por Rogers (1959). A congruência permite que o participante (ou aluno) veja o pesquisador (ou professor) como um "ser humano real", com suas qualidades e defeitos, suas capacidades e limitações. "Ele é uma pessoa, não um corpo sem rosto com uma exigência curricular ou um tubo estéril através do qual o conhecimento é passado de uma geração para a seguinte" (Rogers, 1959, p. 237) ${ }^{10}$.

Em diversos momentos o pesquisador compartilha suas experiências privadas (boas ou ruins), e os participantes, ao observarem determinadas correlações e situações comuns entre os depoimentos do pesquisador (e também dos demais integrantes) com suas próprias experiências, sentem-se mais confortáveis tanto em relatar quanto em tocar com maior desenvoltura e motivação. A aceitação positiva incondicional consiste em aceitar cada indivíduo tal como ele se apresenta, com sua personalidade e subjetividade, proporcionando um ambiente favorável a uma atuação mais livre, permitindo, segundo Rogers, a elaboração das experiências dos indivíduos segundo seus próprios entendimentos e sentimentos (Rogers, 1959, p. 234). $\mathrm{Na}$ compreensão empática, buscamos sentir o mundo privado dos participantes (suas angústias, seus medos etc.), colocando-se no lugar do

\footnotetext{
${ }^{9}$ Como bem observa Aranha (1990), os valores estão na base de todas as nossas ações, e a reflexão sobre os sistemas de valores estabelecidos torna-se fundamental à práxis educativa (Aranha, 1990, p. 119).

${ }^{10}$ Original: "He is a person, not a faceless embodiment of a curricular requirement or a sterile pipe through which knowledge is passed from one generation to the next".
} 
outro, procurando, através desse compartilhamento, entender seus sentimentos e vivências pessoais.

A identificação dos princípios axiológicos - item (b) - é realizada por meio de respostas a perguntas simples, tais como: "Você se considera uma pessoa criativa musicalmente? Por quê?", "Quais as qualidades necessárias para sermos considerados musicais e criativos?", " $E$ difícil improvisar ou compor música? Por quê?", dentre outras. Ao respondê-las, os participantes geralmente expressam suas visões de mundo e seus valores internalizados resultantes de suas experiências e relações socioculturais. Tais principios axiológicos evidenciam, por vezes, inibidores criativos associados às crenças e aos esquemas formulados pelos participantes durante suas experiências vividas. Individuos, por exemplo, que compreendem a criatividade em um sentido extremamente stricto (valorando-a como uma super-habilidade inerente a poucas pessoas que possuem conhecimentos altamente especializados), provavelmente terão um autoconceito como sujeitos criativos mais negativo, se comparados àqueles que a entendem em um sentido mais lato (como uma capacidade intrinseca ao ser humano e capaz de ser desenvolvida). A partir da identificação de valores considerados mais prejudiciais ao desenvolvimento criativo, dá-se início ao processo de rastreamento de pensamentos, crenças e esquemas pessoais, conforme veremos a seguir.

\section{ANÁlisE DOS DEPOIMENTOS DE UM RESPONDENTE A PARTIR DO MODELO COGNITIVO}

Os depoimentos apresentados a seguir foram realizados no sexto encontro da oficina de música. Até esse momento, os participantes já tinham expressado alguns valores relacionados à criatividade musical, à musicalidade, dentre outros tópicos. Apesar da grande maioria manifestar valores construtivos, alguns integrantes informaram baixa autoestima e autoconceito negativo como sujeitos criativos. Nesse texto destacamos os relatos pessoais de um desses participantes, o qual, durante uma conversa em grupo, afirmou não ser criativo, ratificando novamente sua convicção em um ulterior questionário escrito. A conversa abaixo foi efetivada por meio de uma entrevista individual, sem a presença dos demais participantes da oficina. A fim de proteger sua privacidade, não divulgaremos o nome do respondente, atribuindo a sigla $\mathrm{R}$ para respondente e $\mathrm{P}$ para pesquisador:

P: Você afirma que não se considera criativo musicalmente porque suas criações sempre acabam no mesmo lugar. O que você quer dizer?

$\mathrm{R}$ : Como eu falei naquele dia, eu acabo cantando bastante, mas eu percebo que sempre fica a mesma cantoria.

$\mathrm{P}$ : E por que você acha que isso acontece?

R: Não sei, acho que é falta de criatividade. 
P: Você está me afirmando que não consegue criar nada diferente do que você já faz? Por exemplo, suponhamos que você costuma repetir sempre um mesmo ritmo. Se eu lhe pedir para cantar outro ritmo, você não conseguiria?

R: Conseguiria, sim!

P: Então?

Durante a conversa, o respondente esclarece melhor o seu pensamento, especificando de que se trata de uma improvisação vocal que costuma realizar em uma única música (um samba):

R: Eu fico imaginando uma improvisação nessa música, e, sempre quando eu canto ela, eu vejo que começo do mesmo jeito.

O modelo cognitivo não busca afirmar que todos os pensamentos a respeito de uma dada situação são falsos. Em determinados momentos, os respondentes podem, sim, estar corretos com relação ao que pensam. Porém, é necessário proceder uma investigação. Segundo Leahy (2008), pensamentos são hipóteses, descrições, perspectivas e até adivinhações que podem se revelar verdadeiras ou falsas (Leahy, 2008, p. 27). Em um primeiro momento, se considerarmos que a criatividade envolve o pensamento divergente, o respondente poderia estar correto com relação aos seus limites criativos. Contudo, ele não considerou uma série de fatores que poderiam levá-lo a repetir a mesma melodia vocal, dentre eles:

a) A subordinação da melodia à harmonia, a qual pode induzi-lo a se prender nas mesmas notas do acorde;

b) A sua região vocal pode conduzir o canto a uma tessitura confortável para ele e, consequentemente, repetitiva;

c) O respondente relata que nunca tentou improvisar essa mesma música em seu instrumento (o que poderia estimulá-lo a buscar novas sonoridades), ou seja, a sua autoavaliação se fundamenta em uma única atitude vocal que pode não necessariamente estar relacionada com uma limitação de ordem imaginativa.

Além disso, conforme aponta Leahy, ao acreditar em seu pensamento, o sujeito pode, talvez, reagir de maneira desesperançada (sentimento), evitando cantar, compor e/ou improvisar, gerando um comportamento mal adaptado conduzido por seu sentimento (Leahy, 2008, p. 27). O trecho do discurso a seguir evidencia esse comportamento, além de apresentar uma nova informação que respalda o pensamento do respondente:

P: E, ao imaginar melodias, você nunca imaginou uma composição própria?

R: Já imaginei, sim, mas eu não sei se é um problema comigo mesmo, eu sempre acho as minhas melodias feias.

P: Você não gosta do que você imagina? 
R: Não gosto, não, e talvez por isso eu não faça tanto. Mas já fiz e não gostei muito do resultado.

P: Mas só o fato de você imaginar uma melodia, mesmo não gostando dela, faz você acreditar que não é criativo?

R: Sim, eu não sou criativo pelo fato de eu não gostar do que eu crio.

P: E por que você não gosta? Você compara a sua criação com outras músicas?

R: Não sei, é que eu sou meio inseguro e eu acabo me criticando duramente.

É possivel perceber possiveis indícios de ativação de crenças associadas ao desamparo, podendo gerar pensamentos de incapacidade, ineficiência, impotência (Beck, 2014, p. 254). Apesar disso, o respondente realiza uma autoavaliação positiva ao entender-se como inseguro e exageradamente autocrítico, levantando a hipótese de que talvez seja o seu autojulgamento equivocado que o esteja levando a depreciar suas criações musicais. Ao realizar uma investigação sobre seu histórico de aprendizagem durante a entrevista, constatou-se que ele pouco (ou talvez nunca) vivenciou aulas de música que valorizassem quaisquer aspectos criativos (performance criativa, improvisação, composição etc.). $O$ interlocutor aprendeu seu primeiro instrumento (corneta) em fanfarras, limitando-se a executar notas escritas e melodias incompletas. Nesse período, por não ter contato com outras práticas musicais, nunca teve interesse em improvisar ou criar, despertando essa motivação somente na idade adulta, quando começou a tocar trombone em uma big band:

R: Me despertou a improvisação depois que eu entrei na big band. Eu acho bem legal a pessoa improvisar, e ai me despertou essa vontade. Mas, ao mesmo tempo que me despertou, eu vi uma barreira muito grande em relação às cifras... de harmonia eu não sei nada... e aí eu vejo uma barreira grande por causa disso. Mas o laboratório está me ajudando um pouco nisso.

P: No laboratório você conseguiu improvisar em harmonias mesmo sem conhecê-las, não é?

R: Sim.

P: Mas eu entendo, você sente a necessidade de saber harmonia para improvisar dentro de gêneros específicos como samba e jazz, não é? No laboratório, por ser mais livre, você não se sente tão...

R: Preso.

Contudo, no decorrer da conversa, o respondente chamou a atenção para um evento que aconteceu durante a oficina de música ${ }^{11}$ :

\footnotetext{
11 Nesse dia o pesquisador contextualizou a atividade aos participantes, informando que o foco era estabelecer um diálogo musical sem, necessariamente, submeter o material sonoro a um vínculo tonal. Os músicos podiam tocar quaisquer escalas, estando elas ou não relacionadas aos acordes que estavam sendo tocados no momento da improvisação, obtendo, assim, novas sonoridades.
} 
R: Eu acho importante saber harmonia. Até porque, como acontece no laboratório, quando eu vou por mim, eu fujo muito e acaba ficando umas coisas bem estranhas. Tanto é que teve um dia que a gente fez uma improvisação, e eu saí um pouco chateado porque eu não gostei. Depois, no outro dia, você até falou que gostou.

P: Aquele dia que você aplicou uma escala bem diferente do acorde?

R: Sim, eu não gostei, saí bravo.

P: E quando eu falei que gostei?

R: Deu um alivio, mas não me agradou muito... quando eu comecei a música, não estava rolando [a escala não estava encaixando no acorde], e eu fiquei muito nervoso, e, quando a música estava acontecendo, eu já não estava prestando atenção porque o pessoal não estava conseguindo entender, e eu não estava conseguindo criar algo que o pessoal conseguisse entender. Aî eu fiquei nervoso e saí bem bravo.

Apesar de o significado público da atividade ter sido esclarecido (a não necessidade de um vínculo tonal para a realização musical), o significado privado do interlocutor focou exclusivamente em sua dificuldade em estabelecer esse vínculo tonal (atribuindo sua falha à falta de conhecimento de harmonia) e no diálogo musical não estabelecido, segundo sua interpretação. Mesmo o pesquisador apontando evidências que comprovam a sua capacidade criativa, a ênfase de sua fala estava em uma situação de ineficiência, relatando reações emocionais e pensamentos automáticos trazidos à tona durante a performance, conforme Quadro 2:

\begin{tabular}{c|c|c}
\hline Situação & $\begin{array}{c}\text { Pensamentos } \\
\text { automáticos }\end{array}$ & Reações emocionais \\
\hline Improvisação coletiva & $\begin{array}{c}\text { Não consigo encontrar a } \\
\text { escala certa/ O grupo } \\
\text { não está conseguindo } \\
\text { tocar comigo / Não } \\
\text { estou conseguindo criar } \\
\text { algo que eles entendam }\end{array}$ & $\begin{array}{c}\text { Nervosismo / } \\
\text { Indignação }\end{array}$ \\
\hline
\end{tabular}

Quadro 2: Possíveis pensamentos automáticos e reações emocionais.

Indubitavelmente, a atitude criativa não exime a autocritica, o estudo aprofundado e o entendimento de que há problemas a serem resolvidos. Contudo, ao operamos nossas crenças associadas somente ao desamparo, tendemos a adquirir uma sensação de incompletude permanente, além de interpretar as diversas situações vividas exclusivamente através das lentes desse esquema, denegando todas as evidências que o refutam ou não percebendo as condições situacionais e ambientais que podem ter contribuído para nossas limitações atuais (como a própria maneira que se 
deu a formação musical do respondente, por exemplo). A pesquisa empírica realizada nesta investigação tem evidenciado que muitos músicos tendem a se autoavaliar com base em valores que acreditam ser fundamentais à ação criativa, muitos destes sendo os principais responsáveis por seus bloqueios criativos, como por exemplo:

a) A ideia de que a criação musical (mesmo improvisada) deve fluir de maneira automática e sem falhas;

b) A criatividade associada somente a ações musicais inovadoras (performance, composição, improvisação etc.) e sendo também valorada como uma capacidade rara e inata. Ocorre, por vezes, autocomparações com profissionais experientes ou pessoas com habilidades extremamente desenvolvidas, promovendo a desmotivação e a baixa autoestima quando os sujeitos não conseguem alcançar os parâmetros idealizados;

c) A formulação de um padrão estético de criação/improvisação a ser seguido (normas sociais ${ }^{12}$ ). Se o sujeito não atinge esse padrão, não se considera criativo;

d) O conhecimento técnico (percepção musical, habilidade técnicoinstrumental, estudo teórico aprofundado etc.) como imperativo, e não uma ferramenta à ação criativa. O indivíduo não se permite criar ou se expressar musicalmente porque acredita ser necessário um conhecimento prévio altamente especializado para tal ação.

Se o indivíduo, por exemplo, se autoavalia com base no item (a) - a ação criativa não deve ter falhas -, suas crenças centrais tenderão a refletir esse valor, como por exemplo: "pessoas criativas não cometem falhas" (crença sobre os outros), "não sou criativo porque sou falho" (crença sobre si mesmo). Logo, suas crenças subjacentes refletirão os pressupostos/regras de suas crenças centrais: "se eu cometo erros, logo não sou criativo".

As conversas e as práticas criativas realizadas na oficina de música tendem a deixar mais evidente quais os princípios axiológicos que se conectam às crenças que os participantes têm sobre si mesmos, sobre os outros e sobre o mundo. A contestação e a reconstrução de suas crenças se dão através de conversas direcionadas (exame dos sistemas de valores, estímulo à curiosidade e desafio, mostra de evidências que refutam pensamentos disfuncionais, realização de perguntas socráticas etc.), mas também através de práticas musicais, ou seja, do "fazer" e da experiência criativa, possibilitando aos participantes vislumbrar seus plenos potenciais. No decorrer das conversas e performances musicais, observa-se mudanças significativas nos pensamentos e comportamentos da maior parte dos

\footnotetext{
12 Pesquisas realizadas por Asch demonstram que a conformidade com as normas sociais pode influenciar os indivíduos a realizarem ações segundo o estabelecido pelo meio social, e não como realmente desejam agir (Asch, 1955, p. 5).
} 
indivíduos. O depoimento final do interlocutor realizado no último encontro da oficina sugere, por exemplo, uma modificação e a reavaliação de seus valores e crenças:

R: O laboratório me libertou de algo que eu achava que era obrigatório para fazer improvisação e que eu inclusive me privava de fazer por não ter conhecimento teórico. E fizemos tantas coisas legais que pra mim tá mais que provado que não é o mais importante. Antes eu achava que era ruim o fato de, quando tentava improvisar, me desligar por total do resto, e a entrega é muito importante, porque a música vem de dentro e expressa a pessoa que tá tocando por inteiro. (Questionário escrito, encontro 9).

No depoimento acima o respondente afirma que possuía a crença de que sua falta de conhecimento teórico não o permitia se arriscar criativamente (improvisar). Percebe-se que, durante boa parte de suas vivências musicais anteriores à oficina, o item (d) - conhecimento técnico especializado como imperativo, e não ferramenta à ação criativa - era um valor presente em seus pensamentos e crenças; sem excluir a possibilidade dos princípios axiológicos (a), (b) e (c) também estarem internalizados em seu consciente e inconsciente, contribuindo para a sua autoavaliação negativa como sujeito criativo. Contudo, ao considerar o item (d), o interlocutor provavelmente operava a crença central de que "o conhecimento teórico é imperativo à criatividade" (crença sobre o mundo) e/ou que "pessoas criativas devem ter conhecimento teórico" (crença sobre os outros) e, consequentemente, a crença subjacente "se não tenho conhecimento, portanto não sou criativo". Boa parte das justificativas apresentadas em seus depoimentos anteriores ("mesma cantoria", "não gosto do que eu crio") foram, provavelmente, influenciadas por suas crenças centrais. Tais crenças são consideradas disfuncionais porque foram justamente elas que impossibilitaram sua livre expressão musical. Músicos que não operam tais crenças frequentemente se manifestam criativamente desde o início de seus estudos musicais, não vendo problemas em se expressarem a partir do conhecimento disponivel que possuem.

Todavia, as crenças do participante se justificam na medida em que suas experiências musicais anteriores possivelmente lhe apresentaram uma perspectiva pedagógica e sociocultural focada no objeto acima do sujeito e na supervalorização do aspecto intelectual do ser humano em detrimento de seu aspecto existencial. Porém, ao vivenciar diversas performances musicais bem-sucedidas a partir de seu conhecimento disponivel durante a oficina, rompeu-se, ao menos em parte, o ciclo de desamparo, possibilitando-o contemplar suas próprias capacidades expressivas e criativas. Indubitavelmente, há limites para inferir se houve alguma mudança significativa em sua autopercepção como sujeito criativo, uma vez que há toda uma experiência de vida anterior que pode ter gerado crenças centrais 
mais profundas, muitas destas talvez suscitadas mesmo antes das primeiras aprendizagens musicais. Contudo, acreditamos que essa forma de abordagem pode ter auxiliado no começo dessa mudança, estimulando o questionamento e a autorreflexão do interlocutor, tanto na relação consigo mesmo quanto na relação com os outros e com a realidade que o cerca.

\section{CONSIDERAÇÕES FINAIS}

Muitas são as situações que podem imprimir valores e influenciar o comportamento dos indivíduos. As relações socioculturais, o menor ou maior contato com a liberdade, além dos diversos fatores apontados anteriormente neste artigo, afetam cada pessoa de maneira singular. $O$ modelo cognitivo possibilita, assim, ao educador rastrear e identificar valores, pensamentos e crenças que os participantes indubitavelmente trazem consigo desde o primeiro encontro em sala de aula. Se partirmos do principio de que a perspectiva construtivista entende que cada individuo constrói seu mundo psíquico de modo sui generis, sendo, portanto, merecedor de respeito e da mais alta consideração (Arias; Yera, 1996, p. 14); o modelo cognitivo aqui proposto poderá se apresentar, então, como uma valiosa ferramenta para a realização de um trabalho focado na subjetividade humana. Ao colocarmos o ser humano como centro do processo, possibilitamos efetivamente que suas experiências de vida e de aprendizagem sejam a base para a construção de seu próprio conhecimento.

Acreditamos que a utilização do modelo cognitivo, assim como a explicação de seu funcionamento para os estudantes, pode contribuir para que os estudantes reflitam e questionem sobre eventuais pensamentos disfuncionais que estes venham a ter sobre suas capacidades musicais. $O$ modelo pode ser inserido como uma ferramenta em práticas educativas mais humanistas, as quais permitem que os estudantes compartilhem seus pensamentos e emoções, com o intuito de que estes possam ser trabalhados ao longo do processo de ensino. Seja ao estudar um instrumento, ao praticar uma improvisação ou em quaisquer assuntos que permeiem o desenvolvimento musical, diversos pensamentos disfuncionais referentes à música podem surgir, visto que estes podem ocorrer devido às dificuldades no aprendizado em si ou derivados de experiências prévias do indivíduo. Ao permitir que o estudante se expresse em relação a esses pensamentos, ele e o professor podem desenvolver mecanismos que permitam questionar e trabalhar diretamente tais crenças ${ }^{13}$.

Em conclusão, acreditamos que os resultados advindos deste trabalho poderão contribuir para o conhecimento na medida em que sinalizam a relevância de uma pedagogia voltada para uma educação musical capaz de buscar uma maior compreensão empática quanto ao mundo interno do

\footnotetext{
${ }^{13}$ Ressalta-se que questões psicológicas mais complexas e profundas, que estão além de situações de ensinoaprendizagem, devem ser conduzidas por um profissional da saúde mental.
} 
estudante, tendo, como princípio fundamental, o respeito à sua subjetividade. Com base nessas premissas, o educador interessado em realizar esse tipo de abordagem poderá, então, incluir esta ferramenta ao seu trabalho pedagógico, adaptando os procedimentos aqui apresentados à sua realidade educacional.

\section{REFERENCIAS}

ALBINO, César A. C. A importância do ensino da improvisação musical no desenvolvimento do intérprete. 2009. 207 f. Dissertação (Mestrado em Música) - Instituto de Artes, Universidade Estadual Paulista, São Paulo, 2009.

ALENCAR, Eunice S.; FLEITH, Denise S. Criatividade: múltiplas perspectivas. 3. ed. Brasília: UNB Editora, 2003.

ALLSUP, Randall E.; BENEDICT, Cathy. The problems of band: an inquiry into the future of instrumental music education. Music Education Review, v. 16, n. 2, p. 156-173, 2008.

AMABILE, Theresa M.; HENNESSEY, Beth A.; GROSSMAN, Barbara S. Social Influences on Creativity: The Effects of Contracted-for Reward. Journal of Personality and Social Psychology, v. 50, n. 1, p. 14-23, 1986.

ARANHA, Maria L. A. Filosofia da educação. 2. ed. São Paulo: Moderna, 1990.

ARIAS, José O. C.; YERA, Armando P. O que é a pedagogia construtivista? Revista Educação Pública, v. 5, n. 8, p. 11-22, 1996.

ASCH, Solomon. Opinions and Social Pressure. Scientific American, v. 193, n. 5 , p. 31-35, 1955.

BECK, Aaron T. Cognitive Therapy and the Emotional Disorders. New York: Meridian Books, 1976.

BECK, Aaron T.; ALFORD, Brad A. O poder integrador da terapia cognitiva. Tradução Maria Monteiro. São Paulo: Artes Médicas, 2000.

BECK, Aaron T.; HAIGH, Emily A. P. Advances in Cognitive Theory and Therapy: the Genetic Cognitive Model. Annual Review of Clinical Phycology, n. 10, p. 1-24, 2014.

BECK, Judith S. Terapia cognitivo-comportamental: teoria e prática. 2. ed. Tradução Sandra Rosa. Porto Alegre: Artmed Editora, 2014.

BONFORTE, John. The Philosophy of Epictetus. New York: Philosophical Library, 1955. 
BURNARD, Pamela. Musical creativities in practice. Oxford: Oxford University Press, 2012a.

. Rethinking "Musical creativity" and the notion of multiple creativities in music. In: ODENA, Oscar (Ed.). Musical creativity: insights from music education research. United Kingdom: Ashgate, 2012b. p. 5-28.

CAMINHA, Renato M.; VASCONCELLOS, Jorge L. C. Os processos representacionais nas práticas das TCCs. In: CAMINHA, Renato M.; WAINER, Ricardo; OLIVEIRA, Margareth; PICCOLOTO, Neri M. (Eds.). Psicoterapias cognitivo-comportamentais: teoria e prática. São Paulo: Casa do Psicólogo, 2003. p. 23-28.

CANDY, Linda. Practice Based Research: a guide. Creativity and Cognition Studios. Report 1, 2006.

CSIKSZENTMIHALYI, Myhali. Flow and Psychology of Discovery and Invention. New York: Harper Perennial, 1996.

FESTINGER, Leon. The Theory of Social Comparison Processes. Human Relations, v. 7, n. 2, p. 117-140, 1954.

GLASER, Scheilla Regina. Instrumentista \& professor: contribuições para uma reflexão acerca da pedagogia do piano e da formação do músicoprofessor. 2005. 216 f. Dissertação (Mestrado em Música) - Instituto de Artes, Universidade Estadual Paulista, São Paulo, 2005.

. Criatividade na aula de piano: múltiplas facetas. Revista A, São Paulo, Unesp, v. 1, mar. 2007.

HILL, Juniper. Rebellious pedagogy, ideological transformation, and creative freedom in Finnish contemporary folk music. Ethnomusicology, v. 53, n. 1, 2009.

Becoming creative: insights from musicians in a diverse world. New York: Oxford University Press, 2018.

HOUAISS, Antônio (Ed.). Novo dicionário Houaiss da língua portuguesa. Versão monousuário 3.0. Rio de Janeiro: Objetiva, 2009. CD-ROOM.

LEAHY, Robert L. Técnicas de terapia cognitiva: manual do terapeuta. Tradução Maria Veronese e Luzia Araújo. São Paulo: Artmed, 2008.

MASLOW, Abraham H. Toward a Psychology of being. New York: Van Nostrand, 1968.

PEREIRA, Melanie; RANGÉ, Bernard P. Terapia Cognitiva. In: RANGÉ, Bernard (Ed.). Psicoterapias cognitivo-comportamentais: um diálogo com a psiquiatria. 2. ed. São Paulo: Artmed, 2011. 
ROGERS, Carl Significant Learning in Therapy and in Education. Educational Leardership, v. 16, p. 232-242, 1959.

. Toward a Theory of Creativity. In: ANDERSON, Harold H. (Ed.).

Creativity and its Cultivation. New York: Harper \& Row, 1969. p. 69-82.

ROGERS, Carl; KINGET Marian. Psicoterapia \& relações humanas. 2. ed. Tradução Maria Bizzotto. Belo Horizonte: Interlivros, 1977.

SANTOS, Camila E. M.; MEDEIROS, Francisco A. A relevância da técnica de questionamento socrático na prática cognitivo-comportamental.

Arch Health Invest, v. 6, n. 5, p. 204-208, 2017.

SIMONTON, Dean K. Creativity: Cognitive, Personal, Developmental, and Social Aspects. American Psychologist, v. 55, n. 1, p. 151-158, 2000.

SKAINS, Lyle. Creative practice as research: discourse on methodology. Media Practice and Education, v. 19, n. 1, p. 82-97, 2018.

STERNBERG, Robert J. The Nature of Creativity. Creativity Research Journal, v. 18, n. 1, p. 87-98, 2006.

WINNICOTT, Donald W. Leaving Creatively. In: WINNICOTT, Clare; SHEPHERD, Ray; DAVIS, Madeleine (Eds.). Home is where we start from: essays by a psychoanalyst. New York: Norton, 1990. p. 39-54.

YOUNG; Jeffrey E.; KLOSKO, Janet S.; WEISHAAR, Marjorie E. Terapia do Esquema: guia de técnicas cognitivo-comportamentais Inovadoras. Tradução Roberto Costa. Porto Alegre: Artmed, 2008. 
Luciano da Costa Nazario é técnico em música e atua junto a Pró-Reitoria de Extensão e Cultura da Universidade Federal do Rio Grande. Mestre em Música pela Universidade Federal da Bahia e doutor em Música pela Universidade Estadual de Campinas. Atua como regente, arranjador e coordenador do projeto de extensão e cultura Big Band da FURG e como líder do Grupo de Estudos sobre Criatividade em Música, o qual busca compreender a complexidade dos fenômenos envolvidos tanto no desenvolvimento quanto na inibição da criatividade em música. Como pesquisador, busca aperfeiçoar e difundir técnicas, métodos e procedimentos que permitam qualificar o desempenho criativo de estudantes de música. Realizou apresentações orais, palestras e workshops tratando sobre criatividade em música em eventos científicos no Brasil, Argentina, Irlanda, Costa Rica, Peru e China. https://orcid.org/0000-0003-4435-6693

Eduardo Teixeira Martins é estudante de Psicologia na Universidade Federal do Rio Grande e estagiário no Programa Primeira Infância Melhor, realizando visitas domiciliares para desenvolver atividades lúdicas com crianças de 0 a 4 anos com o intuito de auxiliar na promoção de suas capacidades e promover assistência social. Participou do I Fórum Internacional Novas Abordagens em Saúde Mental e da I Jornada de Terapia Sistêmica de Pelotas. Participa do Grupo de Estudos sobre Criatividade em Música, composto por pesquisadores e estudantes de diversas áreas do conhecimento. https://orcid.org/0000$\underline{0002-2761-1763}$

Alex Sandro Rodrigues Martins é estudante de Psicologia na Universidade Federal do Rio Grande. Em 2017 colaborou com a conversa pública "reconstruindo memórias", realizada na prefeitura de Rio Grande, projeto apoiado e sustentado pela Appoa (Associação Psicanalítica de Porto Alegre), que visa acolher os testemunhos de pessoas afetadas pela ditadura civilmilitar no Brasil. Atuou como voluntário na creche e Casa da Criança Mansão da Paz, onde realizou projeto de música e canto com as crianças de várias turmas. Atualmente é bolsista SMED (Secretaria Municipal de Educação) no Centro de Atenção Integral à Criança e ao Adolescente (Caic/FURG) e participa do Grupo de Estudos sobre Criatividade em Música da Furg. https://orcid.org/0000-0002-1675-7185 